\title{
Gustav Mahler in opereta
}

\author{
Primož Kuret \\ Univerza v Ljubljani \\ University in Ljubljana
}

Ko sem pred leti pripravljal svojo knjigo o Mahlerju, dirigentu, ki je eno sezono preživel v ljubljanskem Deželnem gledališču, ${ }^{\mathrm{I}}$ sem bil presenečen, kolikšno število predstav oper in operet je v eni sezoni moral tu pripraviti. Za današnje pojme nepojmljivo število. Žal pa ne vemo nič o njegovem tedanjem bivanju v Ljubljani. Tudi njegovih pisem iz tega obdobja ni. Gledališče je nekaj let po Mahlerjevem odhodu (1887) pogorelo in z njim vred vsi arhivi. Kot mlad, neizkušen dirigent, je moral v eni sezoni, ki je trajala od začetka septembra 1881 do začetka aprila 1882, kljub razumljivi neizkušenosti, prevzeti veliko breme obveznosti. Ljubljansko gledališče je bilo sicer vsekakor bolj urejeno kot gledališče v Bad Hallu, kjer je začel svojo dirigentsko kariero. Toda veljalo je za provincialno gledališče, kakršnih je bilo v monarhiji veliko. Vendar Kurt Blaukopf ugotavlja da je bila Ljubljana provinca z nivojem. ${ }^{2}$ Tudi ohranjeni dokumenti - pogodbe med deželnim odborom in gledališčem - dokazujejo urejenost in resno delo gledališča.

Gledališča v Budimpešti, na Dunaju in v New Yorku, kjer je pozneje deloval, so uprizarjala samo opere in balete, medtem ko so bili repertoarji drugih gledališč pisana mešanica oper, operet, burk in spevoiger. Tudi v Ljubljani so v tej sezoni imeli na programu poleg oper in operet seveda spevoigre in burke. V gledališču so bile tudi slovenske predstave. V Kasslu je Mahler v dveh letih vodil ca. 160 oper in ca. 100 spevoiger poleg drugih na-

1 Primož Kuret, Mahler in Ljubljana (1881-1882) (Ljubljana: DZS, 1997).

2 Kurt Blaukopf, Gustav Mahler oder der Zeitgenosse der Zukunft (München: Deutscher Taschenbuch Verlag, 1973), 54. 
log. ${ }^{3} \mathrm{~V}$ Olomoucu je bil Mahler samo $65 \mathrm{dni}$ in je v tem času stopil za pult samo 15-krat. Med skladatelji je najbolj cenil Mozarta in Wagnerja, ki ju je največkrat izvajal. ${ }^{4}$

Kakšen je bil njegov odnos do operete, komaj kaj vemo iz skopih podatkov, ki so na voljo. V ljubljanskem obdobju o tem ni mogel kaj dosti razmišljati, saj je bil njegov delovni dan dodobra izpolnjen s pripravami za vedno nove predstave. Operete, ki jih je Mahler dirigiral, so bile deloma aktualne, deloma nastale v prejšnjih generacijah, kamor so sodile zlasti francoske operete. Sekundarna literatura slika Mahlerjev odnos do operete v odtenkih vzvišenosti, ambivalence in sovražnosti. Na splošno so menili, da jih je dirigent dolžan izvajati po nalogu svojega šefa ali zaradi finančnega učinka. Tudi pozneje je $\mathrm{v}$ pismih in anekdotah Mahler le malo omenjal popularno glasbo. Mahlerjev biograf Henry-Louis de la Grange piše o dogodku v dunajski Dvorni operi. Pevec Schröder se je branil peti vlogo Eisensteina v Straussovem Netopirju. Mahler ga je takoj ukoril:

Opereta je preprosto majhna in neobvezujoča opera in mnoga klasična dela imajo tak naziv. Straussovo delo prekaša mnoge v svoji ekscelentni glasbeni dikciji, zato ga mnoga operna vodstva vključujejo v svoj operni repertoar. In vi, gospod Schröder, ste peli že mnoga dela, ki so globoko pod ravnijo Netopirja - recimo Ob Vrbskem jezeru (delo koroškega rojaka Tomaža Košata).s

Drugačno mnenje o Johannu Straussu je Mahler povedal Natalie Bauer - Lechner:

Valčkov ne cenim kot nekaj malovrednega. Pustim jim veljavo $v$ njihovih posebnosti in ljubkih izumih. Ampak tega ne morete imenovati umetnost, saj ima $z$ njo tako malo skupnega kakor ljudska pesem. Kratkosapne melodije od osem do osem taktov, iz katerih ni mogoča nikakršna izpeljava, ne moremo šteti za »kompozicijo«. Če jih primerjamo n. pr. s Schubertovimi Moments musicals, vidimo, da je tu $v$ vodenju in razvoju ter vsebini vsakega takta umetni-

Peter Wehle, Gustav Mahler - langsam, schleppend, stuermisch bewegt (Wien: Kremayr \& Scheriau, 2010), 53.

4 Knud Martner, »Mahler im Opernhaus - Eine Bilamz seiner Bühnentägtigkeit 1880-1910«, v Neue Mahleriana, ur. Günther Weiss (Bern: Verlag Peter Lang, 1997), $163-73$.

5 Navaja Henry-Louis de la Grange, Gustav Mahler, vol. 2: Vienna: The Years of Challenge, 1897-1904 (New York: Oxford University Press, 1995), 182. Tomaž (Thomas) Koschat/Košat je bil znan pisec spevoigre s koroško ljudske tematiko. 
na. Strauss je uboga para $z$ vsemi svojimi melodijami in 'domisleki', od katerih se ne da nič prodati - kot nekdo, ki bi moral živeti od zastavljanja svojega nekaj imetja in bi to storil takoj, medtem ko bi drugi imel malo denarja in veliko denarja vedno, ko bi ga potreboval, $v$ žepu. ${ }^{6}$

Vendar so to izjavo pozneje zanikali, saj je bilo splošno znano, da je Mahler Straussa občudoval. ${ }^{7}$

Obstajajo namigi, da je Mahler osebno užival ob opereti in nekatere celo poznal, čeprav jih ni nikoli dirigiral. Tako v pismu, januarja 1904, ženi Almi omenja Pfitznerjevo opero Roža z vrta ljubezni, o kateri napiše:

Včeraj sem bil torej $v$ vrtu ljubezni. Izvedba je bila dobra in je vseskozi potrdila moje vtise pri branju. Velika razpoloženjska sila, zelo zanimiv kolorit, toda preveč brez forme in zamegljeno. Večni zdriz in prvinska sluz, ki vedno potisne življenje, vendar ga zavira $v$ razvoju. Kreacija uspeva kvečjemu do mehkužcev, vretenčarji ne morejo postati. Človek bi rad vzkliknil kot Kalchas v Lepi Heleni: Rože, nič drugega kot rože. ${ }^{8}$

To opereto je Mahler dirigiral samo v Ljubljani in si vendar zapomnil nekaj poant iz teksta.

Še o enem dogodku, ki se je zgodil na eni od predstav Netopirja v Dvorni operi, poroča tenorist Andreas Dippel:

Strauss je sedel na dirigentskem stolu. Girardi (znan dunajski komik), ki naj bi nastopil šele $v$ zadnjem dejanju, je sedel zaenkrat poleg Mahlerja v zatemnjenem parterju. Mahler je bil molčeč, Girardi pa bi rad klepetal. Sem in tja je pogledal v bliskajoče se očala in resni obraz svojega soseda. Končno reče Mahler: Meni bi bil Cigan baron kot slavnostna predstava ljubši. Vesel, da končno lahko govori, je kar zavrelo iz njega $v$ dunajskem dialektu: Aber ich bitt Sie! »Der Zigeuner Baron«! Hätten s'mi amal den Lohengrin singen lassen! Da hätt'n erst was derlebt! [Pa prosim vas! Cigan ba-

Natalie Bauer-Lechner, Gustav Mahler in den Erinnerungen (Hamburg: K. D. Wagner, 1984), 134 .

7 Erich Wolfgang Partsch in Morten Solvik, ur., Mahler im Kontext/Contextualizing Mahler (Wien: Böhlau Verlag, 2011), 371, https://doi.org/10.7767/boehlau.9783205791201.

8 Henry Louis de la Grange in Günther Weiss, ur., Ein Glück ohne Ruh'. Die Briefe Gustav Mahlers an Alma (München: Goldmann Verlag, 1997), 182-283. 
ron! Ali bi mi vi pustili enkrat peti vlogo Lohengrina! Takrat bi šele kaj doživeli.]?

Mahler te operete ni nikoli dirigiral, poznal jo je lahko po tem, da jo je videl ali da je študiral partituro.

Vrnimo se v Ljubljano, kjer je Mahler dirigiral kar tri operete Johanna Strauss jr., in sicer: Cagliostro in Wien (1875), Netopir (1874) in Veselo vojno, ki je nastala leta 1881. Gledališče je imelo na sporedu štiri operete Franza von Suppéja: Boccaccio (1879), Donna Juanita (1880), Fatinitza (1876) in Flotte Bursche (1863), ter tri operete Jacquesa Offenbacha: Barbe-bleu (1866), La belle Helene (1964), La vie parisienne (1866). Robert Planquette je bil zastopan z opereto Les Cloches de Corneville (1877). Prva operetna predstava, ki jo je Mahler v Ljubljani dirigiral, pa je bila Girofle - Girofla Charlesa Lecocqua.

Z opereto pa se je Mahler ukvarjal tudi v Kasslu (Le Mariage aux lanternes), v Hamburgu in na Dunaju je dirigiral Straussovega Netopirja. ${ }^{10}$

Iz teh podatkov vidimo, da je največ operet dirigiral Mahler prav v Ljubljani. O njegovih operetnih predstavah je pisal nemški časopis v Ljubljani, slovenski nemških predstav niso omenjali. Deželno gledališče je vodil v sezoni 1881/82 Alexander Mondheim - Schreiner. V začetku sezone so vedno na novo angažirali pevce, igralce, režiserje in kapelnika. Orkester je imel 18 glasbenikov, ki so se jim pridružili po potrebi glasbeniki vojaške godbe, s katerimi je imelo gledališče posebno pogodbo. Zbor je štel po sedem moških in sedem ženskih glasov.

Po tedanjih kriterijih naj bi imel orkester za opereto naslednjo zasedbo (primer Boccaccio): po 2 flavti, oboi, klarineta, fagota, 4 rogove, 2 trobenti, 3 pozavne, tolkala in godala.

Pevsko osebje so v Ljubljani v tej sezoni sestavljali dramatična sopranistka Caroline Fischer, prva operetna in mladostna operna pevka Leopoldine Ranek, prva operetna in lokalna pevka Hedwig von Wagner, mezzosopranistka Emma von Sonnleitner, "pojoča mati« v operi in opereti Rosine Wallhof-Bomm, pevka Paula Solmar kot prva junakinja, Johanna von Fallenberg, Theresa Lindenthal, Maria Malleg, karakterni komik in režiser Alexander Mondheim Schreiner, buffo basist in režiser Louis Linori, junaški ljubimec Bruno Felix, Ludwig Auspitz, basist Josef Sprinz, prvi

9 Timothy David Freeze, »'Fit for an Operetta': Mahler and the Popular Music of his Day«, v Mahler im Kontext/Contextualizing Mahler, ur. Erich Wolfgang Partsch in Morten Solvik (Wien: Böhlau Verlag, 2011), 371. 
operni tenor Leopold Telle, operetni in operni lirični tenorist Julius Klein, basist Ernst Unger, prvi baritonist Ottokar Payer, baritonist Wenzel Petro, kapelnik August Mahler, direktor orkestra Georg Mayar. ${ }^{\text {II }}$ Sestav ansambla se je med sezono spreminjal.

Ohranjena pogodba med Deželnim gledališčem in Deželnim odborom, podpisana 27. aprila 1881, določa, da je umetniško vodstvo operet, iger in veseloiger izključno v skrbi gospoda Alexandra Mondheim Schreinerja, opera pa v skrbi g. Emanuela Urbana. Posebni člen je določal, da mora gledališki podjetnik zagotoviti z angažiranim osebjem zasedbo, ki zagotavlja popolno in zelo dobro izvedbo. Vsa določila te pogodbe kažejo, kot smo že rekli, na urejeno gledališče.

Mahler je sezono pričel $\mathrm{z}$ izvedbo Beethovnove uverture Egmont in $\mathrm{z}$ izvedbo Verdijeve opere Trubadur. Sledila je nora groteska iz špansko-mavrskega srednjega veka, opereta Girofle-Girofla Charlesa Lecocqua, ki so ga imeli za Offenbachovega naslednika. Kot piše kritik predstave je bil "orkester pod Mahlerjevim vodstvom poln zagona “. ${ }^{\mathrm{I2}}$

Naslednja predstava je bila Straussova opereta Netopir, delo, ki zahteva vrhunske pevce in igralce ter je že v tem času slovelo kot ena najboljših operet dunajskega mojstra Straussa jr. V nasprotju z drugimi ne obravnava pravljičnih snovi, ampak sega $\mathrm{v}$ prikaz meščanskega razreda tega časa. Kritik je predstavo označil »kot $v$ celoti zelo posrečeno«. Za čuda pa Mahlerja ni posebej omenjal. ${ }^{13}$

Podobno velja za naslednjo opereto von Suppéjevo Fatinitzo iz leta 1876 , zgodbo iz krimskih vojn 1854/55. Kritik jo imenuje »neuničljiva Fatinitza« in je bil navdušen nad pevskimi dosežki. Zlasti hvali finale v prvem in tretjem dejanju, pri čemer je prispeval "zelo pošten delež« orkester. ${ }^{14}$

O predstavi Jacquesa Offenbacha Pariško življenje je menil, da je popoln polom preprečil orkester. Vodil ga je seveda Mahler. ${ }^{\text {Is }}$

11 Laibacher Zeitung, št. 56 (10. marec 1881), http://www.dlib.si/?URN=URN:NBN:SI:doc-YDZGV4MS.

12 Laibacher Zeitung, št. 227 (6. oktober 1881), http://www.dlib.si/?URN=URN:NB$\mathrm{N}: S I: d o c-R I M M K O 61$.

13 Laibacher Zeitung, št. 237 (18. oktober 1881), http://www.dlib.si/?URN=URN:NB$\mathrm{N}: S I$ :doc-CGEDE95F.

14 Laibacher Zeitung, št. 250 (3. november 1881), http://www.dlib.si/?URN=URN:NB$\mathrm{N}: \mathrm{SI}: \mathrm{doc}-\mathrm{CMB}_{2} \mathrm{OS} 38$.

15 Laibacher Zeitung, št. 258 (12. november 1881), http://www.dlib.si/?URN=URN:NBN:SI:doc-D845RN8J. 
Po vrsti oper je sledila spet opereta. Tokrat Strraussov Cagliostro na Dunaju, ki je bil po kritikovem mnenju »dobro naštudiran in je lepo uspel «. ${ }^{16}$

Pred novim letom so se vrstile na odru seveda predvsem operete. V Netopirju in Boccacciu je nastopila kot gostja Amelie Mara iz Bratislave in zelo poživila predstavo.

S Suppéjevo operete Boccaccio pa je gledališče doseglo prebojen uspeh. Naslovno vlogo genialnega pripovednika iz zgodnje renesanse je skladatelj namenil ženskemu glasu in v Ljubljani jo je pela »odlično« altistka Hedwig von Wagner. Navdušenje občinstva je bilo veliko in je po tretjem dejanju priklicalo ansambel kar trikrat pred zaveso. Skladatelju je finančni uspeh te operete omogočil, da se je posvetil samo komponiranju. Vendar podobnega uspeha $z$ drugimi operetami predvsem zaradi šibkih libretov ni več dosegel. - Na koncu pohvalne ocene ljubljanski kritik opozarja tudi na slovensko predstavo v gledališču s tremi enodejankami: Zapirajte vrata, Eno uro doktor in Krojač Fips in pričakuje prav številen obisk. ${ }^{17}$

Tudi Suppéjeva opereta Veseli fantje (Flotte Bursche) sodi med manj uspele. Nastala je že leta 1863. V uverturi citira skladatelj znano pesem Gaudeamus igitur. V ljubljanski predstavi je kritik pohvalil poleg nekaterih solistov predvsem zbor. ${ }^{18}$

V prednovoletni predstavi Netopirja je ponovno uspešno nastopila pevka Amelia Mara kot Rosalinda, ki je navdušila $z$ lepim glasom in »res graciozno igro«. Novo angažirani tenorist Friedrich Erl je briljiral s pesmijo Glücklich ist, wer vergisst. Prav Erl je med ljubljanskimi kolegi naredil najbolj uspešno kariero in nastopal po številnih evropskih odrih. Znano je, da je v Mannheimu pel na premieri Wolfovega Corregidorja. Kritik je zelo pohvalil ansambel v drugem dejanju, zlasti izvedbo valčka Brüderlein und Schwesterlein. »V celoti je predstava potekala precizno. " ${ }^{19}$

Kmalu po novem letu je sledila Offenbachova "razuzdana" opereta Lepa Helena z Leopoldino Ranek v glavni vlogi. Kritik je bil v glavnem s predstavo in pevci zadovoljen, orkestra in Mahlerja pa posebej ne omenja.

16 Laibacher Zeitung, št. 279 (7. december 1881), http://www.dlib.si/?URN=URN:NB$\mathrm{N}: \mathrm{SI}: \mathrm{DOC}-9402 \mathrm{NSH} 2$.

17 Laibacher Zeitung, št. 265 (21. november 1881), http://www.dlib.si/?URN=URN:NB$\mathrm{N}: \mathrm{SI}$ :doc-QHE6UA73.

18 Laibacher Zeitung, št. 292 (23. december 1881), http://www.dlib.si/?URN=URN:NB$\mathrm{N}: \mathrm{SI}: \mathrm{doc}-\mathrm{XH} 4 \mathrm{GDCU} 6$.

19 Laibacher Zeitung, št. 296 (29. december 1881), http://www.dlib.si/?URN=URN:NB$\mathrm{N}: \mathrm{SI}:$ doc-SYD50NXG. 
Sezona se je prevesila $\mathrm{v}$ drugo polovico in pevci so dobivali svoje benefične predstave. Tako si je Eugen Berger izbral opereto Mornariški kadet Richarda Geneea (1823-1895). Skladatelj je bil rojen v Gdansku, nato pa 20 let nastopal kot operni dirigent, skladatelj in gledališki kapelnik po različnih evropskih odrih. Leta 1868 je bil angažiran v dunajskem Theater an der Wien, kjer se je uveljavil kot libretist operet m. d. Johanna Straussa, Millöckerja in Suppéja. Med njegovimi deli je opereta Mornariški kadet nastala že leta 1850. Ljubljanska predstava je bila slabo obiskana, tudi vsi pevci niso bili na običajni ravni, pač pa je bil zbor in celoten igralski ansambel v drugem dejanju "natančno izveden." Predstavo bi morali naslednji dan ponoviti, pa so zaradi bolezni namesto nje izvedli Verdijevo opero Ernani. Pozneje so predstavo vendarle ponovili $\mathrm{z}$ uspehom, saj je $» v s a$ predstava potekala $v$ redu . $^{20}$

$\mathrm{Na}$ novo so naštudirali opereto Cornevillski zvonovi skladatelja $\mathrm{R}$. Planquetta, »ki jo je občinstvo pohvalno sprejelo. Celotni vtis je bil prav ugoden, zlasti so ugajali kostimi in kritik je bil prepričan, da bo gotovo doživela še nekaj repriz«. ${ }^{21}$

Ljubljana je rada sledila novostim. Tako je kmalu po premieri Straussove operete Vesela vojna, ki je bila na Dunaju konec leta 1881, uprizorila to delo že 28. februarja 1882. Svoj čas je je ta opereta pomenila kar enega od vrhov Straussove muze in tudi v Ljubljani so bili nad njo silno navdušeni. Kritik v Laibacher Zeitung se je o delu na široko razpisal, časopis je v podlistku obširno citiral mnenje znamenitega dunajskega glasbenega kritika Eduarda Hanslicka. Kritika je bila temu primerno navdušena in že na začetku poudarila izjemen uspeh tako zaradi lepih melodij kot zaradi »briljantne» opreme. Hiša je bila razprodana, lože prenapolnjene in vsi so pričakovali, da orkester zaigra uverturo. In že ta je občinstvo spodbudila k viharnemu aplavzu. In ko se je nato dvignil zastor, so si sledile scene za sceno, soli in dueti, trio in kvinteti, zbori in finale ... Zelo pohvalno pa kritik spet omenja Mahlerja:

Tudi orkester moramo danes pohvaliti, saj se je pod dobrim vodstvom g. kapelnika Mahlerja hrabro držal. [...] Kapelnik Mahler je dobil tudi zase in za svoj orkester viharno priznanje. ${ }^{22}$

20 Laibacher Zeitung, št. 16 (20. januar 1882), http://www.dlib.si/?URN=URN:NB$\mathrm{N}: \mathrm{SI}:$ doc-UO66AKT4.

21 Laibacher Zeitung, št. 25 (31. januar 1882), http://www.dlib.si/?URN=URN:NB$\mathrm{N}: \mathrm{SI}:$ doc-T96 $88 \mathrm{OS}_{3}$.

22 Laibacher Zeitung, št. 49 (1. marec 1882), http://www.dlib.si/?URN=URN:NBN:SI:doc-PI529DXH. 
Do konca sezone so opereto Vesela vojna ponovili enajstkrat, kar priča o njeni priljubljenosti in uspehu predstave. Ob tej predstavi je treba omeniti še eno novost. Predstavo so prenašali $\mathrm{z}$ odra prek telefona v gledališko direkcijo. Mahler se je tako že v Ljubljani prvič srečal s tehničnim prenosom predstav.

Tudi Gustav Mahler je imel svojo benefično predstavo. Izbral si je opero Alessandro Stradella, ki opisuje pustolovsko življenje italijanskega baročnega skladatelja. Na predstavo je opozoril časopis Laibacher Zeitung že dan pred njo:

Kapelnik gospod Mahler ima svojo benefično predstavo. Izbral si je letos še ne izvajano priljubljeno opero Alessandro Stradella. Sposobnemu in delovnemu dirigentu naše opere, operete in spevoiger, ki je imel $v$ sezoni dosti truda in muke želimo zelo dober obisk. ${ }^{23}$

Po predstavi pa je omenil, da je bil Mahler

neumorno delaven in prizadeven kapelnik. Opera je bila dobro naštudirana in izvedena. Ko se je beneficiant pojavil, sta ga sprejela precej številno zbrano občinstvo z živahnim aplavzom in orkester s tušem. Dobil je velik lovorjev venec kot znamenje priznanja. Ta odlično šolani glasbenik jemlje svoje naloge zelo resno. Med sezono je imel mnogo težav in skrbi ter si je venec tudi popolnoma zaslužil. ${ }^{24}$

Mahler je v Ljubljani predstavil 15 operet v 42 predstavah in 11 oper na 40 predstavah. V kratkem času od začetka oktobra 1881 pa do konca marca 1881 je dirigiral kar 82 predstav, kar je moralo tako za njega kakor za ansambel predstavljati precejšen napor. Kritike so večkrat ugotavljale pomanjkljivosti, slabše sposobnosti posameznih pevcev, ki so jih med sezono po potrebi tudi zamenjali, medtem ko o orkestru, zboru in dirigentu takih pripomb ni. V svoji nadaljnji bogati dirigentski karieri pa se je Mahler repertoarju, ki ga je dirigiral v Ljubljani, striktno in če je le bilo mogoče izogibal (Rossini, Gounod, Flotow, Donizetti in operete). Posamezne predstave so bile tudi v Ljubljani na sporedu tudi samo enkrat (Le Fille de madam Angot, Barbe-bleu, La belle Helene, Flotte Bursche). Po dvakrat so izvedli operete Mornariški kadet (Der Seekadet), Girofle-Girofla, La vie parisi-

23 Laibacher Zeitung, št. 66 (21. marec 1882), http://www.dlib.si/?URN=URN:NBN:SI:doc-AINBY $59 \mathrm{~N}$.

24 Laibacher Zeitung, št. 69 (24. marec 1882), http://www.dlib.si/?URN=URN:NBN:SI:doc-FLI76IZV. 
enne, Cagliostro in Wien, Netopir, in Fatinitza. Kornevilski zvonovi so zvonili v Ljubljani trikrat, Boccaccia so peli petkrat, Donno Juanito sedemkrat, medtem ko je bila Vesela vojna uprizorjena kar enajstkrat. Nekaj operet je nastalo neposredno pred uprizoritvijo v Ljubljani (Cagliostro in Bocccaccio - 1879, Dona Juanita - 188o, Vesela vojna - 1881), druge, predvsem Offenbachove operete, so bile starejšega datuma. Vsekakor pa lahko rečemo, da je bila na Ljubljana na tekočem $\mathrm{z}$ opero in opereto.

\section{Bibliografija}

Bauer-Lechner, Natalie. Gustav Mahler in den Erinnerungen. Hamburg: K. D. Wagner, 1984.

Blaukopf, Kurt. Gustav Mahler oder der Zeitgenosse der Zukunft. München: Deutscher Taschenbuch Verlag, 1973.

Freeze, Timothy David. »'Fit for an Operetta': Mahler and the Popular Music of his Day«. V Mahler im Kontext/Contextualizing Mahler, urednika Erich Wolfgang Partsch in Morten Solvik. Wien: Böhlau Verlag, 2011.

Grange, Henry-Louis de la. Gustav Mahler, vol. 2: Vienna: The Years of Challenge, 1897-1904. New York: Oxford University Press, 1995.

Grange, Henry Louis de la in Günther Weiss, ur. Ein Glück ohne Ruh'. Die Briefe Gustav Mahlers an Alma. München: Goldmann Verlag, 1997.

Kuret, Primož. Mahler in Ljubljana (1881-1882). Ljubljana: DZS, 1997.

Laibacher Zeitung (1881-1882).

Martner, Knud. »Mahler im Opernhaus - Eine Bilamz seiner Bühnentägtigkeit 1880-1910«. V Neue Mahleriana, urednik Günther Weiss, 163-73. Bern: Verlag Peter Lang, 1997.

Partsch, Erich Wolfgang in Morten Solvik, ur. Mahler im Kontext/Contextualizing Mahler. Wien: Böhlau Verlag, 2011. https://doi.org/10.7767/ boehlau.9783205791201.

Wehle, Peter. Gustav Mahler - langsam, schleppend, stuermisch bewegt. Wien: Kremayr \& Scheriau, 2010. 